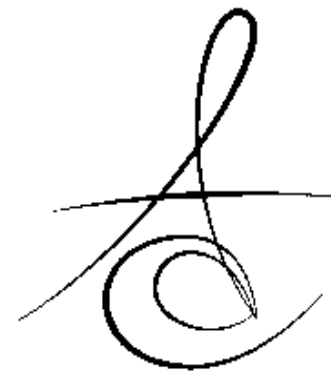

\title{
SONLU ELEMANLAR STRES ANALİZi VE RESTORATİF DİŞ HEKİMLİĞİNDE KULLANIMI
}

\author{
FINITE ELEMENTS STRESS ANALYSIS AND ITS USE IN RESTORATIVE \\ DENTISTRY
}

\section{Dr. Ertan TAŞKINSEL*}

\author{
Yrd. Doç. Dr. Hasan Önder GÜMÜŞ**
}

Makale Kodu/Article code: 1099

Makale Gönderilme tarihi: 24.02.2013

Kabul Tarihi: 21.03.2013

\section{ÖZET}

Stres analizi yöntemleri ağız içi biyomekaniğin daha iyi anlaşılmasına yardımcı olarak, daha başarılı restorasyonlar yapılabilmesine imkan verdikleri için diş hekimliği araştırmalarında uzun süredir kullanılmaktadır. Sayısal bir teknik olan sonlu elemanlar stres analizi tekniği, kullanılan diğer tekniklere göre çeşitli avantajları nedeniyle ve bilgisayar teknolojisindeki gelişmelerin de etkisiyle son yıllarda diş hekimliği araştırmalarında oldukça popüler bir kullanım alanına sahip olmuştur. Bu derleme çalışmasında sonlu elemanlar stres analizi ve restoratif diş hekimliğindeki uygulama alanlarıyla ilgili genel bir bakış açısı sunulmaya çalışılmaktadır.

Anahtar kelimeler: Sonlu elemanlar stres analizi, Stres dağılımı, Restoratif diş hekimliği

\section{ABSTRACT}

Stress analysis techniques are being used in dental research for a long time because of allowing more successful restorations by giving an aid to a better understanding of biomechanics in oral environment. Because of several advantages compared to other techniques, and the effect of developments in computer technology, finite element stress analysis technique has become very popular in dental research in recent years. This article efforts to give a general overview about finite element stress analysis and its use in restorative dentistry.

Keywords: Finite element analysis, Stress distribution, Restorative dentistry

- Lazer ışınlı yöntem

- Holografik interferometre ile analiz yöntemi

- Sonlu elemanlar stres analizi (SESA) yöntemi

Sonlu elemanlar stres analizi canlı dokular da dahil olmak üzere tüm materyallerde meydana gelen stres (gerilim) ve gerinimleri (strain) hesaplamada kullanılabilen matematiksel bir mühendislik metodudur. SESA'de analiz edilecek canlı ya da cansız yapıların modellemesi gerçeğe en yakın şekilde yapılarak matemetiksel olarak ifade edilir. Bilgisayar teknolojisinin gelişmesiyle araştırmalarda bu metodun kullanılması da popülerleşmiştir. Bilgisayar desteği ile yapılan bu analiz diğer analizlere göre daha detaylı ve gerçeğe daha yakın sonuçlar vermektedir. SESA yönteminde analizi yapılacak yapı sonlu sayıdaki

*Kuşadası Devlet Hastanesi Diş Tedavi ve Protez Merkezi Aydın

**Erciyes Üniversitesi Diş Hekimliği Fakültesi Protetik Diş Tedavisi Anabilim Dalı 
parçalara bölünerek kuvvet karşısındaki durumu matematiksel olarak incelenir. Bilgisayar yardımıyla oluşturulan modelde, belirlenen şiddet, yön ve alandaki kuvvet uygulamasına bağlı olarak ortaya çıkan şekil değişiklikleri, stres dağıımı ve şiddetleri saptanmaktadır. ${ }^{2,3}$

SESA ilk olarak 1956 yılında havacılık endüstrisinde kullanılmaya başlanmış ve günümüzde havacılık ve uzay mühendisliği, otomotiv sektörü, biyomedikal, jeoteknik, elektromanyetik, hidrolik ve nükleer enerji mühendisliği alanlarında rutin olarak kullanılmaya devam etmektedir. ${ }^{4,5}$ Bu yöntem sayesinde katı bir cisim olan diş incelenebildiği gibi, bir sıvı olan kan ve damarlardaki akışı da araştırılabilmektedir. ${ }^{6}$

Laboratuvarda yapılan testlere göre SESA yönteminin çeşitli avantajları vardır. Bu yöntemde değişkenlerle kolaylıkla oynanabilir, insan materyaline ihtiyaç duyulmaz ve maksimum standardizasyon sağlar. ${ }^{4}$ SESA yönteminin diğer avantajları arasında sonlu elemanların boyutlarının ve şekillerinin çeşitliliği nedeniyle bir cismin geometrisinin tam olarak temsil edilebilmesi, bir veya birden çok bölgenin incelenebilmesi, değişik malzeme ve geometrik özellikleri bulunan cisimlerin kolaylıkla incelenebilmesi, sınır şartlarının kolayca uygulanabilmesi ve yöntemin çok yönlülüğü ve esnekliği sayesinde karmaşık yapılarda sebep sonuç ilişkilerini hesaplamak için çok etkin bir şekilde

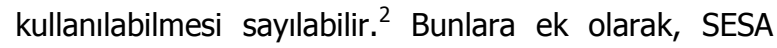
yöntemi diğer birçok yönteme göre daha az zaman alıcıdır. $^{5}$

SESA yönteminin dezavantajları olarak ise, analizde kullanılan bilgisayar programlarının yüksek maliyetlere sahip olabilmeleri ve çoğu zaman bu analizi yapmak için uzman kişilere intiyaç duyulması sayılabilir. ${ }^{5}$

SESA genellikle iki boyutlu veya üç boyutlu modeller kullanılarak yapılır. İki boyutlu SESA yönteminin uygulanması daha kolaydır ve çok gelişmiş bilgisayar sistemlerine intiyaç duyulmaz. Ancak özellikle karmaşık geometriye sahip yapıların analizinde çok doğru sonuçlar vermeyebilir. Üç boyutlu SESA yönteminde tüm eksenlerdeki kuvvetler hesaba katılacağı için gerçeğe daha yakın sonuçlar elde edilmesi olanaklıdır. ${ }^{3}$

SESA lineer veya non-lineer sistemlere uygulanabilir. Lineer sistemler daha basit sistemlerdir ve plastik deformasyon hesaba katılmaz. Non-lineer sistemlerde plastik deformasyon ve çoğu zaman materyalin kırılması da test edilebilir. ${ }^{7}$ Bütün cisimler belirli bir kuvvet sınırından sonra elastik deformasyondan plastik deformasyona geçerek şekil değiştirirler. Bundan dolayı lineer sonlu elemanlar stres analiz yönteminin plastik deformasyonları göstermemesi ilk anda bir dezavantaj olarak görülebilir. Ancak proprioseptif refleks, diş ve çevre dokuları plastik deformasyona sokabilecek kuvvetlerin bir defada oluşmasını engeller. ${ }^{8}$ Bu nedenle diş hekimliğinde yapılan araştırmalarda kullanılan kuvvetler genelde elastik deformasyon sınırları içindedir. Non-lineer SESA ise lineer statik modelle çözülemeyen gerçekçi durumlardaki stres ve straini araştırmak için gittikçe daha güçlü bir yaklaşım haline gelmektedir. ${ }^{9}$

SESA yönteminin uygulanmasındaki temel aşamalar sırasıyla şunlardır:

1. Yapının modellenmesi ve elemanlara bölünmesi

2. Analiz verilerinin yüklenmesi

3. Analizin çözümlenmesi

\section{1-Yapının Modellenmesi ve Elemanlara Bölünmesi}

Öncelikle analizde kullanılacak tüm yapılar bilgisayar ortamına aktarılarak bir geometrik model oluşturulur. Geometrik modeller bilgisayar destekli tasarım programları kullanılarak elde edilir ve karmaşık yapıların modellenmesinde, üç boyutlu bilgisayarlı tomografi tarayıcısı veya üç boyutlu lazer tarayıcısından faydalanılabilir.

Hazırlanan geometrik model mümkün olduğunca fazla sayıda elemana bölünür. Eleman sayısı ne kadar çok olursa analizde gerçeğe o kadar yakın sonuçlar elde edilebilir. ${ }^{10}$ Elemanlar tek boyutlu (düz çizgiler), iki boyutlu (üçgenler, eşkenar dörtgenler) veya üç boyutlu (piramit veya tuğlaya benzer şekilli) ve değişik şekillerde olabilirler. ${ }^{5}(S ̧ e k i l$ 1) Elemanların birbirlerine bağlandıkları noktalara düğüm (node), tüm yapıya ise ağ (mesh) denmektedir. (Şekil 2) ${ }^{11,12}$

Sonlu elemanlar modeli gerçek bir objenin matematiksel modeli olduğundan doğal davranışın tüm detaylarının aktarılması mümkün olmayabilir. Ancak model bilgisayar ortamında olduğu için değişkenler ve yükleme koşulları istenildiği gibi değiştirilebilir. Bu nedenle iyi oluşturulmuş bir matematiksel model, yapılacak analiz için çok değerli bir araçtır. ${ }^{13}$ 


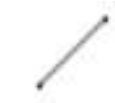

Nonet.
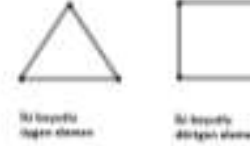

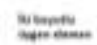

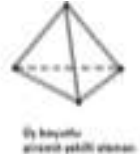

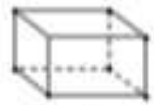

$4=$
Şekil 1: SESA yönteminde kullanılan eleman örnekleri
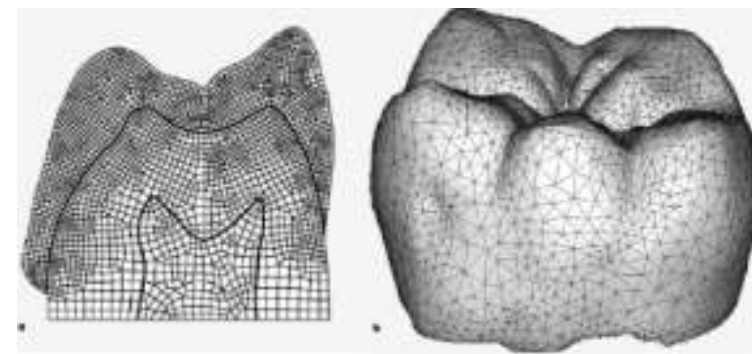

Şekil 2: iki boyutlu (a) ve üç boyutlu (b) SESA modellemelerine örnekler

\section{2-Analiz Verilerinin Yüklenmesi}

Bu aşamada modellemesi yapılan elemanların materyal özellikleri, yükleme koşulları ve sınır şartları programa yüklenir. Gereken minimum materyal özellikleri poisson oranı ve young modülü iken inceleme konusuna göre genleşme katsayısı, sürtünme katsayısı, termal iletkenlik gibi değerler de kullanılabilir. ${ }^{7}$ Oluşturulan modelin belirli düğüm noktalarından sabitlenmesiyle sağlanan yer değiştirme kısıtlamaları ve yükleme koşulları sınır şartlarını oluşturmaktadır.

\section{3-Analizin Çözümlenmesi}

Her elemanın iç çözümlemesinden tüm yapının çözümlemesine bilgisayar programları yardımılla ulaşılır. Analiz sonucunda elde edilen stress değerleri matematiksel hesaplamalar sonucunda edilmektedir ve bu değerlerin varyansı bulunmamaktadır. Bu nedenle bu değerlerin istatistiksel analizi yapılamamaktadır. Sonuçlar dikkatli bir şekilde incelenerek yorumlanır. SESA yönteminde stresin sayısal değeri doğru olmayabilir ama stresin hangi bölgede ve ne kadar oluşacağı sorusuna cevap bulunabilmektedir. ${ }^{13}$

SESA yönteminin diş hekimliğindeki uygulamaları aşağıdaki şekilde sınıflandırılabilir: ${ }^{14}$

- Dental materyaller

- Diş Dokusu (mine, dentin, sement)

- Amalgam

- Kompozit rezin ve simanlar
- Cam, seramik ve porselen

- Metaller ve metal sistemleri

- Diğerleri

- $\quad$ Oral ve maksillofasiyal mekanik ve cerrahi

- Mandibula

- Temporomandibular eklem

- Periodontal ligament, alveolar kemik

- Diğerleri

- Ortodonti, diş hareketleri, ortodontik apareyler

- Kök kanalları, kök kanal dolguları ve bu dişlerin tedavileri

- Dental restorasyonlar

- Dolgular

- Kronlar, köprüler

- Tam ve parsiyel protezler

- Dental implantlar

- Diğerleri (SESA modellemeleri)

Diş hekimliğinde SESA yöntemi kullanılarak bir çok araştırma yapılmıştır. Aşağıda özellikle restoratif tedavi alanında SESA yöntemi kullanılarak yapılan çalışmalardan kronolojik sıraya göre örnekler verilmiştir.

1978 yllında Wright ve Yettram ${ }^{15}$ alt ikinci büyük azı dişte amalgam uygulaması ve ISIsal genleşme sırasındaki mekanik davranışını, aynı yıl Dayangaç $^{16}$ amalgam dolguların kırıma olasılığını azaltabilecek MOD kavite şeklini iki boyutlu SESA yöntemiyle incelemişlerdir.

Üç boyutlu SESA yönteminin kullanıldığı ilk çalışma 1983 yılında Rubin ve ark. ${ }^{17}$ tarafından gerçekleştirilmiş ve bu çalışmada bir alt sağ birinci büyük azı diş modellenip mine ve dentindeki sıkışma gerilimleri incelenmiştir.

1983 'te Peters ve ark. ${ }^{18}$ iki boyutlu olarak modellenen bir ikinci küçük azı dişte post çapının, post boyu ve şeklinin, post ve siman arasındaki etkileşimin dişteki gerilmeler üzerindeki etkilerini araştırmışlardır. Spierings ve ark. ${ }^{19} 1984$ 'te restoratif diş malzemelerinin insan dişindeki Isı iletimi üzerindeki etkilerini iki boyutlu olarak bir alt büyük azı diş modeli üzerinde incelemiştir.

1995 yllında Ersöz, ${ }^{20}$ porselen ve kompozit laminate veneerlerin iki ayrı kuvvet uygulanması durumundaki stres dağııımını, aynı yıl De Hoff ve ark. ${ }^{21}$ dentin-kompozit birleşiminde bağlayıcı ajanların makaslama gerilmelerini üç boyutlu SESA yöntemi kullanarak göstermişlerdir. 
1999 yilında Rees ve Jacobsen ${ }^{22}$ kaspal gerilimlerin bukkal V. Sınıf restorasyonlara etkisini, 2001 yılında Yakar $^{23}$ farklı kompozit rezinlerin V. sınıf kavitelerdeki stres dağılımına etkilerini aynı yöntemle incelemişlerdir. 2004 yılında Misra ve ark. ${ }^{24}$ total etch adeziv içeren dentin-adeziv arayüzünü iki boyutlu olarak modelleyip, bu arayüzde oluşan stresleri SESA yöntemiyle belirlemişlerdir.

2005 yılında Belli ve ark. ${ }^{25}$ kompozit ve seramik inley uygulanmış premolar dişteki streslere hibrit tabakanın etkilerini incelerken üç boyutlu SESA yöntemini kullanmışlardır.

2007 yılında Anchieta ve ark. ${ }^{26}$ self etch adeziv içeren dentin adeziv ara yüzünü iki boyutlu olarak modelleyip, bu ara yüzde oluşan stresleri SESA yöntemiyle incelemişlerdir.

Silva ver ark. $27 \quad 2009$ yılında yaptıkları çalışmada metal ve fiberglass postlarla restore edilmiş üst santral dişteki stres dağılımını incelemişlerdir. Aynı yıl Taşkınsel ${ }^{28}$ rezin-dentin ara yüzünde oluşan stresleri üç boyutlu SESA yöntemi kullanarak incelemiştir.

May ve ark. ${ }^{29} 2012$ yılında yaptıkları çalışmada siman kalınlığı ve bondingin CAD/CAM seramik kronlardaki stres dağılımı ve başarısızlık üzerindeki etkilerini SESA yöntemi ve laboratuvar testi yardımıyla incelemişlerdir.

\section{SONUÇ}

Daha başarılı restorasyonlar yapılabilmesi için ağız içi biyomekaniğinin de iyi anlaşılması gereklidir. Bu konuda stres analizi yöntemlerinden yararlanılabilir. Gerçeğe daha yakın sonuçlar vermesi, daha az zaman alıcı olması gibi avantajlarından dolayı SESA yöntemi restoratif diş hekimliği ve diş hekimliğinin diğer alanlarında sıklıkla başvurulan bir stres analizi yöntemi olmaya devam etmektedir. Sürekli gelişen bilgisayar teknolojisi bu yöntemin uygulanabilirliğini kolaylaştırmakta ve kullanımını popülerleştirmektedir.

\section{KAYNAKLAR}

1. Craig R. Restorative Dental Materials. Mosby Co St.Louis

2. Sonugelen $M$, Artunç $C$. Ağız Protezleri ve Biyomekanik In: Proceedings of the: Ege Üniversitesi Diş Hekimliği Fakültesi Yayınları, 2002:
1-11.

3. Geng JP, Tan KB, Liu GR. Application of finite element analysis in implant dentistry: a review of the literature. J Prosthet Dent 2001; 85: 585-98.

4. Srirekha A, Bashetty K. Infinite to finite: an overview of finite element analysis. Indian J Dent Res 2010; 21: 425-32.

5. Shetty P, Hegde AM, Rai K. Finite element method-an effective research tool for dentistry. J Clin Pediatr Dent 2010; 34: 281-5.

6. Yaman SY. Sonlu elemanlar yöntemi ve dishekimliginde uygulamalar Atatürk Üniversitesi Dishekimliği Fakültesi Dergisi 1995; 1:87-96.

7. Prasad K, Tarannum SA. Basic Principles of Finite Element Method and its Applications in Orthodontics. Journal of Pharmaceutical and Biomedical Sciences 2012; 16(: 1-4.

8. Estafan D, Schulman A, Calamia J. Clinical effectiveness of a Class $V$ flowable composite resin system. Compend Contin Educ Dent 1999; 20: 1115; quiz 16.

9. Wakabayashi N, Ona M, Suzuki T, Igarashi $Y$. Nonlinear finite element analyses: advances and challenges in dental applications. J Dent 2008; 36: 463-71.

10. Geramy A, Morgano SM. Finite element analysis of three designs of an implant-supported molar crown. J Prosthet Dent 2004; 92: 434-40.

11. Arola D, Galles L, Sarubin M. A comparison of the mechanical behavior of posterior teeth with amalgam and composite MOD restorations. Journal of Dentistry 2001; 29: 63-73.

12. Magne P. Efficient 3D finite element analysis of dental restorative procedures using micro-CT data. dental materials 2007; 23: 539-48.

13. Gümüs HÖ. Üç farklı dental implant yiv tasarımının ve iki farklı dental implant çapının degisik yogunluktaki kemik üzerinde olusturdukları streslerin üç boyutlu sonlu elemanlar stres analizi yöntemi ile karsılastırılması. Doktora Tezi, Hacettepe Üniversitesi, 2007.

14. Mackerle J. Finite element modelling and simulations in dentistry: a bibliography 1990-2003. Comput Methods Biomech Biomed Engin 2004; 7: 277-303. 
15. Wright KW, Yettram AL. Finite element stress analysis of a class I amalgam restoration subjected to setting and thermal expansion. J Dent Res 1978; 57: 715-23.

16. Dayangaç B. Sonlu elemanlar stres analiz yöntemi ile MOD amalgam dolgu kırılma olasılığını azaltabilecek kavite şeklinin incelenmesi. Doçentlik tezi, Hacettepe Üniversitesi, 1978.

17. Rubin C, Krishnamurthy N, Capilouto E, Yi H. Stress analysis of the human tooth using a threedimensional finite element model. J Dent Res 1983; 62: 82-6.

18. Peters MC, Poort HW, Farah JW, Craig RG. Stress analysis of a tooth restored with a post and core. J Dent Res 1983; 62: 760-3.

19. Spierings TA, de Vree JH, Peters MC, Plasschaert AJ. The influence of restorative dental materials on heat transmission in human teeth. J Dent Res 1984; 63: 1096-100.

20. Ersöz E. Farklı laminate veneer yapım tekniklerinin in-vitro olarak mikrosızıntı açısından ve sonlu elemanlar stres analiz yöntemi ile stres dağılımı yönünden değerlendirilmesi Ankara. Doktora Tezi, Ankara Üniversitesi, 1995.

21. DeHoff PH, Anusavice KJ, Wang Z. Threedimensional finite element analysis of the shear bond test. Dent Mater 1995; 11: 126-131.

22. Rees JS, Jacobsen PH. The effect of interfacial failure around a class $\mathrm{V}$ composite restoration analysed by the finite element method. J Oral Rehabil 2000; 27: 111-6.

23. Yakar H. Farklı kompozit rezinlerin V. sınıf kavitelerdeki stres dağılımına etkisinin sonlu elemanlar stres analizi yöntemi ile incelenmesi. Doktora Tezi, Hacettepe Üniversitesi, 2001.

24. Misra A, Spencer P, Marangos O, Wang Y, Katz JL. Micromechanical analysis of dentin/adhesive interface by the finite element method. J Biomed Mater Res B Appl Biomater 2004; 70: 56-65.

25. Belli S, Eskitascioglu G, Eraslan O, Senawongse P, Tagami J. Effect of hybrid layer on stress distribution in a premolar tooth restored with composite or ceramic inlay: an FEM study. J Biomed Mater Res B Appl Biomater 2005; 74: 6658.
26. Anchieta RB, Rocha EP, Ko CC, Sundfeld RH, Martin Junior $M$, Archangelo CM. Localized mechanics of dentin self-etching adhesive system. J Appl Oral Sci 2007; 15: 321-6.

27. Silva NR, Castro CG, Santos-Filho PC, Silva GR, Campos RE, Soares PV, Soares CJ. Influence of different post design and composition on stress distribution in maxillary central incisor: Finite element analysis. Indian J Dent Res 2009; 20: 153-8.

28. Taşkınsel E. Rezin-Dentin Arayüzündeki Streslerin Üç Boyutlu Sonlu Elemanlar Stres Analizi Yöntemiyle İncelenmesi. Doktora Tezi, Hacettepe Üniversitesi, 2009.

29. May LG, Kelly JR, Bottino MA, Hill T. Effects of cement thickness and bonding on the failure loads of CAD/CAM ceramic crowns: multi-physics FEA modeling and monotonic testing. Dent Mater 2012; 28: e99-109.

\section{Yazışma Adresi}

Dr. Ertan TAŞKINSEL

Kuşadası Devlet Hastanesi

Diş Tedavi ve Protez Merkezi

Kuşadası/AYDIN

Tel: 02566182414

Email: benertantask@hotmail.com 